\section{D) Check for updates}

Cite this: Food Funct., 2021, 12, 9820

\title{
Bioactivity screening of pinhão (Araucaria Angustifolia (Bertol.) Kuntze) seed extracts: the inhibition of cholinesterases and $\alpha$-amylases, and cytotoxic and anti-inflammatory activities
}

\author{
Anielle de Oliveira, (D) a Thaysa Fernandes Moya Moreira, ${ }^{a}$ Ana Luisa Silva Pepinelli, ${ }^{b}$

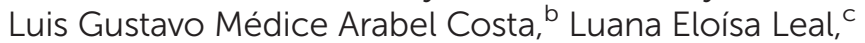 \\ Tamires Barlati Vieira da Silva, iD a Odinei Hess Gonçalves, ${ }^{\text {a,d }}$ Rafael Porto Ineu, ${ }^{a}$ \\ Maria Inês Dias, ID d Lillian Barros, (D) d Rui M. V. Abreu, d Isabel C. F. R. Ferreira, (iD d \\ Lívia Bracht ${ }^{\mathrm{C}}$ and Fernanda Vitória Leimann (D) *a,d
}

\begin{abstract}
The objective of this work was to determine the potential bioactive properties of extracts from bio-residues of pinhão (Araucaria angustifolia (Bertol.) Kuntze) seeds, namely the $\alpha$-amylase and cholinesterase inhibition, cytotoxicity, and anti-inflammatory properties. The pinhão extracts evaluated were obtained from cooking water (CW) and as an ethanolic extract from residual pinhão seed shells (PS). Catechin was the major compound found in both extracts. The PS extract presented higher antioxidant levels and the better inhibition of human salivary and porcine pancreatic $\alpha$-amylases when compared to the CW extract. Also, based on in vivo evaluations, the PS extract did not differ significantly from acarbose when compared to a control group. The most potent inhibitor of cholinesterases was the CW extract. No cytotoxicity toward normal cells was detected, and neither extract showed anti-inflammatory activity. The PS extract presented cytotoxic activity toward non-small-cell lung, cervical, hepatocellular and breast carcinoma cell lines. Overall, the results demonstrated the potential bioactivity of extracts obtained from pinhão bioresidues.
\end{abstract}

\begin{abstract}
Received 15th April 2021, Accepted 4th August 2021 DOI: $10.1039 / \mathrm{d} 1 \mathrm{fo} 01163 \mathrm{~d}$ rsc.li/food-function
\end{abstract}

Diabetes mellitus (DM) is a chronic metabolic disease caused by inherent or acquired deficiencies in insulin secretion or by decreased organ sensitivity in responding to this hormone, generating high levels of glucose in the blood. The increase in the number of diabetics and the adverse effects of some synthetic drugs have contributed to a growing demand for alternative compounds that are relatively cheaper and have fewer side effects. ${ }^{2}$

Conventional treatments include the reduction of insulin demand, the stimulation of endogenous insulin secretion, the improvement of its action in target tissue, and the inhibition of oligosaccharide and disaccharide degradation. ${ }^{3}$ This can be achieved via inhibiting hydrolyzing carbohydrate enzymes, such as $\alpha$-amylase (EC 3.2.1.1) and $\alpha$-glucoside (EC 3.2.1.20), that are present in the gastrointestinal tract, leading to the control of postprandial hyperglycemia. ${ }^{4}$

In addition, another disease that has gained the interest of specialists is Alzheimer's disease (AD), a neurodegenerative disease, the most common symptoms of which are memory loss, cognitive dysfunction, behavioral disorder, and difficulty performing daily and intellectual activities. It is estimated that more than 35 million people in the world suffer from this 
disease and by 2050 this number could rise to more than 115 million individuals. ${ }^{5}$

One hypothesis about the cause of Alzheimer's disease is that it involves the cholinergic system, being characterized by low levels of acetylcholine during cholinergic transmission. It is known that the acetylcholinesterase (EC 3.1.1.7) and butyryl cholinesterase (EC 3.1.1.8) enzymes play a fundamental role in the closure of nerve impulse transmission, as they are responsible for the hydrolysis of acetylcholine and choline. ${ }^{6,7}$ Therefore, the inhibition of cholinesterase enzymes may be an alternative method to regulate cholinesterase levels, ${ }^{8}$ and the use of bioactive compounds for the purpose of modulating these enzymes has been shown to be promising for the minimization of cognitive damage. ${ }^{9}$

Many natural compounds have been studied for the inhibition of enzymes such as cholinesterases, for hydrolyzing carbohydrate enzymes, and for reducing oxidative stress. These bioactive molecules have generated great interest as a result of their potential benefits, largely due to their potent antioxidant activities. ${ }^{10}$ These compounds can be extracted from several natural sources and also from bio-residues. In Brazil, trees popularly known as "Paraná pinhão trees" or "Brazilian pine trees" (Araucaria angustifolia (Bertol.) Kuntze) are responsible for a significant portion of the economy of southern Brazil, and the bio-residues generated during the preparation of pinhão seeds are frequently used in medicine, mainly in the treatment of respiratory diseases. ${ }^{11,12}$ Pinhão seeds are consumed after baking or cooking in water. Both the residual coat (external tegument or shell) and the water extract that results from the cooking process are rich in phenolic compounds and can be explored as bio-residues.

Daudt et al. ${ }^{13}$ conducted a study on the characterization of aqueous pinhão shell extract and observed that it presented significant quantities of phenolic compounds; its use as an antioxidant agent was considered relevant. In another study, Da Silva et al. ${ }^{14}$ applied an extract obtained from pinhão coats ( $70 \%$ ethanol in water) as an inhibitor of $\alpha$-amylase; the authors observed that the tannins in the extract were rich in procyanidins (catechin, epicatechin, and esters of gallic acid), and the extract was considered to be an effective inhibitor of human salivary and porcine pancreatic $\alpha$-amylase. In addition, they found that pinhão coat extract was also effective in decreasing blood glucose levels in Wistar rats after the administration of starch. However, the enzymatic inhibition properties and cytotoxicity of the cooking water residual extract have still not been investigated.

Thus, the purpose of this work is to obtain extracts from pinhão bio-residues (CW: cooking water extract; PS: residual seed shell extract) and assess their properties in terms of the antioxidant capacity, the inhibitory effects toward $\alpha$-amylase enzymes (human salivary and porcine pancreatic enzymes) and cholinesterases (acetylcholinesterase and butyryl cholinesterase), the cytotoxicity toward tumor cell lines, and the anti-inflammatory activity; this work could contribute to the development of new applications of these extracts.

\section{Materials and methods}

\subsection{Materials}

Araucaria angustifolia (Bertol.) Kuntze seeds (pinhão seeds) were acquired from a local market in Campo Mourão, Paraná State, Brazil in April 2018. Ethyl alcohol (Dinâmica) was used for the extraction of antioxidant compounds from the shells. For the analysis of antioxidant capacity, the radical DPPH (2,2diphenyl-picrilhidrazil, Sigma-Aldrich) and methanol (Dinâmica) were used. Human salivary enzymes (type IXA, 87.5 units per $\mathrm{mg}$ of solid, Sigma-Aldrich), porcine pancreatic enzymes (type VI-B, 10 units per mg of solid, Sigma-Aldrich), potato starch (Sigma-Aldrich), sodium tartrate (Alphatec), sodium hydroxide (Isofar), dinitrosalicylic acid (Inlab), calcium chloride (Prochemicals), and sodium phosphate (Vetec) were used for the assessment of the inhibition of $\alpha$-amylases. Cholinesterase activities (AChE and BChE) were determined using trihydroxymethyl aminomethane (Tris-HCl, Dynamic), potassium phosphate buffer (monobasic potassium phosphate, 99.93\%, Neon; dibasic potassium phosphate, $100.3 \%$, Mallinckrodt), DTNB (98\%, Sigma-Aldrich), acetylthiocolin iodide, and $S$-butyrylthiocolin (Sigma-Aldrich). The human tumor cell lines used in cytotoxicity analysis were obtained from the Leibniz DSMZ Institute - German Collection of Microorganisms and Cell Cultures. Acarbose (Glucobay, Bayer Pharma AG) was used as a control. Acetonitrile (Fisher Scientific, HPLC grade) was used in chromatographic analyses, and formic acid was purchased from Panreac Química SLU. The phenolic standards were purchased from Extrasynthèse, and water was treated using a Milli-Q water purification system (TGI Pure Water Systems, USA).

\subsection{Obtaining pinhão extracts}

Pinhão seeds $(500 \mathrm{~g})$ were cooked in water $(1 \mathrm{~L})$ for $2 \mathrm{~h}$, simulating conventional cooking. The extract (cooking water: $\mathrm{CW}$ ) was frozen $\left(-55^{\circ} \mathrm{C}\right)$ and freeze-dried..$^{15}$ In order to obtain the second extract, pinhão shells (PS) were dried in an oven $\left(60^{\circ} \mathrm{C}\right.$, $24 \mathrm{~h}$ ) and then crushed in a knife mill (SOLAB). To complete the extraction, the methodology optimized by Santos et al. was applied $^{16} 200 \mathrm{~mL}$ of ethyl alcohol was added to $17.5 \mathrm{~g}$ of pinhão shells. The solution was stirred in ultra-turrax apparatus (Ika, T25) for $15 \mathrm{~min}$ at $12000 \mathrm{rpm}\left(42.5^{\circ} \mathrm{C}\right)$. Finally, the mixture was filtered with the aid of a vacuum pump and placed in an oven at $50{ }^{\circ} \mathrm{C}$ until the complete evaporation of the solvent had occurred.

\subsection{Thermal and phenolic profile characterization of extracts}

The extracts were subjected to differential scanning calorimetry analysis (DSC, PerkinElmer, 4000). For this, extract samples, previously kept in a desiccator with silica for 1 week, were weighed $(10 \mathrm{mg})$ into aluminum pans. The applied heating ramp process was from 0 to $350{ }^{\circ} \mathrm{C}$ at a heating rate of $10{ }^{\circ} \mathrm{C} \mathrm{min}{ }^{-1}$ under nitrogen gas flow $\left(20 \mathrm{~mL} \mathrm{~min}{ }^{-1}\right)$.

The phenolic profiles of pinhão extracts $\left(10 \mathrm{mg} \mathrm{mL} \mathrm{m}^{-1}\right.$ in water) were determined via HPLC-DAD-ESI/MSn (Dionex Ultimate 3000 UPLC, Thermo Scientific, San Jose, CA, USA). 
Compounds were separated and identified as described previously by Bessada, Barreira, Barros, Ferreira, and Oliveira. ${ }^{17}$ Detection was performed using DAD (280, 330, and $370 \mathrm{~nm}$ were the preferred wavelengths) and a mass spectrometer (MS detection was performed in negative mode, using Linear Ion Trap LTQ XL apparatus, Thermo Finnigan, San Jose, CA, USA). The following calibration curves were used for quantification: $(+)$-catechin $\left(y=84950 x-23200, R^{2}=1\right)$, chlorogenic acid $(y=$ $\left.168823 x-161172, R^{2}=0.9999\right),(-)$-epicatechin $(y=10314 x+$ $\left.147331, R^{2}=0.9994\right)$, ferulic acid $\left(y=633126 x-185462, R^{2}=\right.$ $0.9990)$, naringenin $\left(y=18433 x+78903, R^{2}=0.9998\right)$, and protocatechuic acid $\left(y=214168 x+27102, R^{2}=0.9999\right)$. The results were expressed in units of $\mathrm{mg} \mathrm{g}^{-1}$ of extract.

\subsection{Analysis of antioxidant capacities}

The antioxidant capacity measurements were performed using DPPH as the free radical, following methodology described by Brand-Williams, Cuvelier, and Berset $^{18}$ with some modifications. For this, $50 \mu \mathrm{L}$ of extract was added to $1950 \mu \mathrm{L}$ of DPPH methanolic solution $\left(60 \mu \mathrm{mol} \mathrm{L}{ }^{-1}\right)$ in a test tube. The mixture was kept in the dark for $30 \mathrm{~min}$ and then the absorbance was read at $517 \mathrm{~nm}$ using a spectrophotometer. The final results were obtained by means of the Trolox calibration curve $\left(y=0.0905 x-0.8656 ; R^{2}=0.9984\right)$ and are expressed in units of $\mu \mathrm{mol}$ of Trolox equivalent per $100 \mathrm{~g}$ of extract.

\subsection{In vitro evaluation of human salivary and porcine pancreatic $\alpha$-amylase inhibition}

The determination of $\alpha$-amylase inhibition, in terms of the $\mathrm{IC}_{50}$ value (concentration of extract required to cause 50\% enzyme activity inhibition), was performed according to the methodology described by Da Silva et al. ${ }^{14}$ with some modifications. Pancreatic $\alpha$-amylase (porcine) and human salivary $\alpha$-amylase were solubilized in phosphate buffer $\left(40 \mathrm{mmol} \mathrm{L}^{-1}\right)$ and $\mathrm{NaCl}\left(13.4 \mathrm{mmol} \mathrm{L}^{-1}\right)$ at $\mathrm{pH}$ 6.9. Potato starch was used as a substrate (1\% wt v $\mathrm{v}^{-1}$ in water). Pinhão extracts were evaluated as inhibitors at final concentrations of 2000, 1400, 800, 200, 80 , and $20 \mu \mathrm{g} \mathrm{mL} \mathrm{m}^{-1}$, and the reaction was initiated via the addition of enzyme. The enzyme concentration added to each reaction system was $74 \mathrm{U} \mathrm{mL}^{-1}$ for both enzymes. The reaction was maintained for $15 \mathrm{~min}$ in a temperature-controlled bath at $37{ }^{\circ} \mathrm{C}$. Reducing sugars produced via starch hydrolysis were measured using the dinitrosalicylic acid (DNS) method at a wavelength of $540 \mathrm{~nm} .{ }^{19}$

The method of numeric interpolation with the Stineman equation $^{20}$ was used to calculate the concentration of extract that was able to inhibit enzymatic activity by $50 \%\left(\mathrm{IC}_{50}\right)$. The software used was the Scientist program of MicroMath Scientific Software (Salt Lake City, UT, USA).

\subsection{In vivo evaluation of $\alpha$-amylase inhibition}

The experiments were performed at the Laboratory of Liver Metabolism and Radioisotopes of the State University of Maringá. Before conducting the tests, the work was submitted and accepted by the Ethics Committee on the Use of Animals (CEUA/UEM) under protocol number 2935011018. Rats (Rattus novergicus) of the Wistar line weighing $230 \pm 20 \mathrm{~g}$ were used, which were kept under standard temperature conditions $(22 \pm$ $3{ }^{\circ} \mathrm{C}$ ) with a light/dark cycle of $12 \mathrm{~h}$. The animals received filtered water and commercial feed (Nuvilab®) ad libitum while they stayed in the bioterium. Tests to evaluate the effects of CW and PS extracts on $\alpha$-amylase inhibition in vivo were performed according to the procedure described by Da Silva et $a l .{ }^{14}$ In this procedure, rats fasted for $12 \mathrm{~h}$ and were then divided into 8 groups ( $n=5$ to 7 rats per group), where all received maize starch ( $1 \mathrm{~g}$ per $\mathrm{kg}$ of body weight) dissolved in water followed by treatment (also dissolved in water) via single dose gavage. The treatments were divided into the following groups: group I (control) was treated with the solvent used for the dissolution of the extracts (water); group II received acarbose (50 $\mathrm{mg} \mathrm{kg}^{-1}$ ); groups III, IV, and V received CW extract at concentrations of 100,250 , and $500 \mathrm{mg} \mathrm{kg}^{-1}$, respectively, and groups VI, VII, and VIII were treated with PC extract at the same concentrations as described for CW. Then, blood glucose levels were measured 15, 30, 45, and $60 \mathrm{~min}$ after gavage. Blood samples from the tail veins of animals were analyzed by means of a glucometer (Accu-Check $®$ Active).

\subsection{In vitro analysis of cholinesterase activity inhibition: acetylcholinesterase (AChE) and butyryl cholinesterase (BChE)}

The AChE and BChE activities were measured as described by Ellman et $a .^{21}$ and modified by Silva de Sá et $a .^{22}$ For that, 100 flies (Drosophila melanogaster) were anaesthetized in ice and solubilized in $1 \mathrm{~mL}$ of tris- $\mathrm{HCl}$ solution (0.05 M, pH 7.4); the mixture was centrifuged at $12000 \mathrm{rpm}$ for $10 \mathrm{~min}$, and then the supernatant was collected and stored in an ultrafreezer $\left(-80{ }^{\circ} \mathrm{C}\right)$ for future analysis of cholinesterase activity. Analysis was performed in duplicate using a reaction medium that contained $100 \mu \mathrm{L}$ of potassium phosphate buffer (TFK, $100 \mathrm{mM}, \mathrm{pH} 7.5), 20 \mu \mathrm{l}$ of water, $10 \mu \mathrm{L}$ of supernatant, and $20 \mu \mathrm{L}$ of extract (at final concentrations of $20,14,8$, and $2 \mathrm{mg}$ $\mathrm{mL}^{-1}$ ); a control was also studied (without the addition of extract). First, the medium was incubated at $30{ }^{\circ} \mathrm{C}$ for $5 \mathrm{~min}$, and then $20 \mu \mathrm{L}$ of 5,5'-dithiobis(2-nitrobenzoic acid) (DTNB) and $20 \mu \mathrm{L}$ of acetylthiocholine were added in the dark (for BChE tests, this volume was replaced with the same volume of butyryl thiocholine). Absorbance determinations were performed every minute (for $4 \mathrm{~min}$ ) in a plate reader (ThermoPlate Reader) at a wavelength of $405 \mathrm{~nm}$. The enzymatic activity was expressed as a percentage of activity relative to the control group $(100 \%)$.

\subsection{Evaluation of cytotoxicity toward cell lines and anti- inflammatory activities}

Evaluation of the cytotoxicity of extracts (CW and PS) was performed according to a procedure described by Silva de Sá et al., ${ }^{22}$ using the following human tumor cell lines: breast adenocarcinoma (MCF-7); pulmonary carcinoma (NCIH460); cervical (HeLa); and hepatocellular carcinoma (HepG2). Porcine liver cells (PLP2) were prepared according to methodology described by Abreu et $a .^{23}$ The results were expressed as 
$\mathrm{GI}_{50}$ values (the concentration that inhibited $50 \%$ of the net cell growth).

For determining anti-inflammatory activities, the production of lipopolysaccharide (LPS) induced by nitric oxide (NO) in a murine macrophage line (RAW 264.7) was quantified based on the nitrite concentration in the culture medium. ${ }^{24}$ For NO measurements, the Griess Reagent System kit was used. Dexamethasone was used as a positive control. The results were expressed as $\mathrm{IC}_{50}$ values (the concentration of the compound responsible for $50 \%$ inhibition of nitric oxide production).

\subsection{Statistical analysis}

Statistical analysis of enzymatic tests was performed using GraphPad Prism software version 6.0 (Graph Pad, USA), with analysis of variance (ANOVA), and the result averages were compared using Tukey's test at a 5\% significance level $(p<$ 0.05). Other obtained results were also evaluated with ANOVA and Tukey's test at a $5 \%$ significance level $(p<0.05)$ using Statistica 7.0 software (Statsoft, USA).

\section{Results and discussion}

\subsection{Thermal and phenolic profile characterization of extracts}

Fig. 1 presents the thermograms of the two studied extracts obtained via differential scanning calorimetry.

Endothermic peaks near $80^{\circ} \mathrm{C}$ can be observed in both thermograms; this transition may be related to water evaporation. ${ }^{25}$ In addition, in the PS extract sample, a well-defined peak is observed at approximately $54{ }^{\circ} \mathrm{C}$, which is possibly related to the presence of terpenes that are characteristic of conifers such as Araucaria angustifolia (Bertol.) Kuntze. ${ }^{26,27}$ According to Tsanaktsidis et al. ${ }^{28}$ the glass transition temperature $\left(T_{\mathrm{g}}\right)$ of Pinus halepensi resin is located at $37{ }^{\circ} \mathrm{C}$; however, no thermal characterization data relating to resin could be obtained from Araucaria angustifolia (Bertol.) Kuntze here.

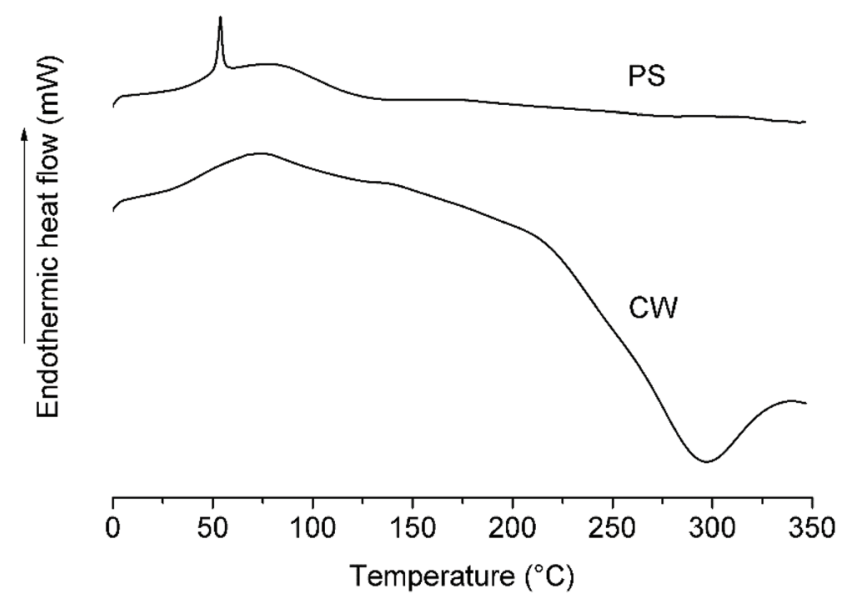

Fig. 1 Differential scanning calorimetry thermograms of PS (pinhão shell) and CW (cooking water) extracts.
Still, there was no thermal degradation of the extracts within the studied range. These results are worth reporting in order to evaluate the possibility of future application via food formulations, which can be subjected to baking or cooking at high temperatures, ${ }^{29}$ or via incorporation into active packaging material, ${ }^{30}$ and to choose encapsulation processes that are compatible with the thermal stability. ${ }^{31}$ Furthermore, DSC is an example of an analytical method used to characterize drugs, compounds, their products, and extracts in the area of herbal medicine. ${ }^{32}$

The phenolic profiles of the extracts (CW and PS) were obtained via HPLC-DAD-ESI/MSn and are shown in Table 1.

The compounds were identified based on their retention time, and UV-vis and mass spectra characteristics. Five compounds were identified, with catechin being the major molecule present in both extracts; these results are in agreement with data reported by Da Silva et al. ${ }^{30}$ who also found eight compounds present in pinhão cooking water extract, with catechin also found at a high concentration. Fonseca et al. ${ }^{33}$ identified 12 compounds in an aqueous extract obtained from pinhão seed coats, with (+)-catechin and a catechin/epicatechin dimer being the major compounds present. De Souza et al. ${ }^{34}$ identified 8 phenolic compounds in pinhão cooking water extract aimed at being applied as a source of antioxidants in active packaging, with protocatechuic acid and (+)-catechin presenting higher concentrations. It is worth noting that the PS extract showed a higher phenolic content than the CW extract, with all identified compounds found at higher concentrations, and the major compounds are highlighted as flavonoids, such as catechin and epicatechin.

\subsection{Antioxidant capacities}

Table 2 shows the results obtained from the analysis of antioxidant capacities via the DPPH method.

It should be noted that the extract from pinhão shells presented an antioxidant capacity that was about 2-fold higher against the radical DPPH when compared to the cooking water extract; this result shows that even after cooking, most of the compounds that act as antioxidants are still present in the shell, and only some of these migrate to the cooking water. This result can be explained based on the higher phenolic content present in pinhão shell extract (Table 1).

De Freitas et al. ${ }^{15}$ evaluated the antioxidant capacity of pinhão water cooking via the DPPH method and obtained a value of $11.78 \mu_{\mathrm{mol}} \mathrm{TE}^{-1}$ of extract, approximately 6 times lower than that obtained in the present study. This difference may be related to differences in the cultivation location, maturation time, and climatic conditions, among other factors that may interfere in antioxidant action. ${ }^{35}$

Mota et al. ${ }^{36}$ analyzed the antioxidant capacities of methanolic extracts of pinhão shells and seeds via DPPH, ABTS, and ORAC methods, observing that the shell extract demonstrated higher antioxidant capacity when compared to the seed extract. Also, the authors identified the presence of molecules, such as polyphenols, flavonoids, and proanthocyanidins, that are able to scavenge free radicals. 
Table 1 Retention time $\left(R_{\mathrm{t}}\right)$, maximum absorption wavelengths in the visible region $\left(\lambda_{\text {max }}\right)$, mass spectra data, tentative identification, and quantification (concentration in $\mathrm{mg}_{\text {compound }}$ per $\mathrm{g}_{\text {extract, }}$ dry weight $(\mathrm{dw})$ ) of the phenolic compounds, and the total phenolic content (TPC) levels present in the pinhão extracts

\begin{tabular}{|c|c|c|c|c|c|c|c|}
\hline & & $\begin{array}{l}\lambda_{\max } \\
(\mathrm{nm})\end{array}$ & $\begin{array}{l}{[\mathrm{M}-\mathrm{H}]^{-}} \\
(\mathrm{m} / \mathrm{z})\end{array}$ & $\operatorname{MS} 2(m / z)$ & Tentative identification & \multicolumn{2}{|c|}{$C\left(\mathrm{mg} \mathrm{g}_{\text {extract }}{ }^{-1}, \mathrm{dw}\right)$} \\
\hline 1 & 4.96 & 260294 & 153 & 109(100) & Protocatechuic acid & $1.47 \pm 0.10$ & $1.52 \pm 0.05$ \\
\hline 3 & 7.56 & 280 & 577 & $451(25), 425(100), 289(15), 287(5)$ & B-type (epi)catechin dimer & $0.71 \pm 0.05$ & $0.86 \pm 0.01$ \\
\hline 4 & 9.66 & 279 & 289 & 245(100), 203(15), 187(26), 161(22), 137(5) & (-)-Epicatechin & $0.68 \pm 0.02$ & $2.00 \pm 0.02$ \\
\hline 5 & 14.7 & 281314 & 449 & $287(100)$ & Eriodictyol-O-hexoside[A42] & tr & $0.22 \pm 0.01$ \\
\hline
\end{tabular}

Table 2 Antioxidant (DPPH), hydrolyzing enzyme, and cholinesterase enzyme activities in the presence of extracts (cooking water: CW; pinhão seeds: PS)

\begin{tabular}{|c|c|c|}
\hline & CW & PS \\
\hline \multicolumn{3}{|l|}{ Antioxidant activity $^{a}$} \\
\hline $\begin{array}{l}\text { DPPH }\left(\mu \text { mol }_{\text {TE }} \text { per } 100 g_{\text {ext }}\right) \\
\text { Hydrolyzing enzyme activity }\end{array}$ & $6987.11^{\mathrm{a}} \pm 170.02$ & $12937.34^{\mathrm{b}} \pm 12.45$ \\
\hline Human saliva $\alpha$-amylase & $740.00 \pm 34.64$ & $129.00 \pm 11.53$ \\
\hline Porcine pancreatic $\alpha$-amylase & $1871.66 \pm 174.81$ & $460.70 \pm 88.90$ \\
\hline Cholinesterase enzyme activity $^{c}$ & & \\
\hline Acetylcholinesterase & $7.31 \pm 0.10$ & $8.09 \pm 0.06$ \\
\hline Butyryl cholinesterase & $1.94 \pm 0.02$ & $6.96 \pm 0.07$ \\
\hline \multicolumn{3}{|c|}{$\begin{array}{l}{ }^{a} \text { Sample averages }(n=3) \text { accompanied by the same letter in the same } \\
\text { (lowercase) line do not differ significantly from each other }(p>0.05) \text { ) } \\
\text { based on Student's } t \text {-test. } \mu \mathrm{mol}_{\mathrm{TE}} \text { per } 100 \text { gext: } \mu \mathrm{moles} \text { of Trolox equi- } \\
\text { valent per } 100 \mathrm{~g} \text { of extract. }{ }^{b} \mathrm{IC}_{50} \text { expressed in } \mu \mathrm{g} \mathrm{mL} \mathrm{mL}^{-1} \cdot{ }^{c} \mathrm{IC}_{50} \text { expressed } \\
\text { in } \mathrm{mg} \mathrm{mL} \mathrm{mL}^{-1} \text {. }\end{array}$} \\
\hline
\end{tabular}

\subsection{In vitro evaluation of human salivary and porcine pancreatic $\alpha$-amylase inhibition}

The $\mathrm{IC}_{50}$ values determined for both extracts in relation to their inhibition capacities toward the activity of hydrolyzing enzymes are presented in Table 2.

It can be noticed that the pinhão shell (PS) extract presented greater inhibitory effects when compared to the cooking water (CW) extract. In fact, it can be verified that the PS extract presented $\mathrm{IC}_{50}$ values approximately 4 -fold smaller than those determined for the WC extract toward both $\alpha$-amylases. This effect is probably related to differences in the bioactive compound concentrations present in the extracts. Pinhão shell extract presented a catechin concentration two-fold higher than the cooking water extract (Table 1). As reported by Da Silva et al., ${ }^{14}$ the procyanidins present in pinhão residues may act as inhibitors of human salivary and porcine pancreatic alpha-amylases.

It is also interesting to note that salivary $\alpha$-amylase is more responsive to inhibition by the extracts than pancreatic $\alpha$-amylase. The PS extract $\mathrm{IC}_{50}$ value determined toward the pancreatic enzyme was 3.5-fold higher when compared to the salivary enzyme. For the WC extract, a 2.5-fold increase in the $\mathrm{IC}_{50}$ value was seen toward the pancreatic enzyme.
Da Silva et al., ${ }^{14}$ when analyzing pinhão shell extract $(70 \%$ ethanolic extract purified via molecular exclusion chromatography), concluded that it demonstrated an effective inhibitory effect toward the activities of salivary and porcine pancreatic $\alpha$-amylases, and the authors attributed this result to the action of condensed tannins, mainly procyanidins.

Other studies have evaluated extracts obtained from seed and nut coats, husks, skins, and peel, and their bio-residues. Zulfqar et $a l .{ }^{37}$ reported the maximum inhibition of $\alpha$-amylase by methanolic and ethyl acetate extracts of Pinus gerardiana at $16 \mathrm{mg} \mathrm{mL} \mathrm{m}^{-1}$, which is higher than the results of this study. Tsujita et $a l^{38}$ fractionated a polyphenolic extract obtained from almond seed skin (Prunus dulcis) using ultrafiltration and Sephadex LH-20 and ODS columns. The purified fraction presented strong inhibitory action against $\alpha$-amylase; the $\mathrm{IC}_{50}$ value determined toward pig pancreatic $\alpha$-amylase was equal to $2.2 \mu \mathrm{g} \mathrm{mL}{ }^{-1}$. In addition, Schmeda-Hirschmann et al. ${ }^{39}$ evaluated the performance of extracts of Araucaria araucana kernels against porcine pancreatic $\alpha$-amylase. The authors expressed the inhibitory action in terms of an inhibition percentage determined for a fixed concentration of $100 \mu \mathrm{g} \mathrm{mL} \mathrm{m}^{-1}$. The values determined by the authors varied from inactive to $33.56 \%$ inhibition depending on the sample origin (8 Chilean regions), collection year $(2017,2018$, or 2019), and processing conditions. The results obtained in the present work are compatible with those obtained by other authors; furthermore it is clear that purified extracts, such as the ones obtained by Tsujita et al., ${ }^{38}$ present more powerful inhibitory action when compared to non-purified extracts.

\subsection{In vivo evaluation of $\alpha$-amylase inhibition}

Fig. 2 shows the glycemic index results from Wistar rats after the ingestion of starch (control) and from those who had also received the extracts (CW and PS) orally. In these experiments, acarbose, a pseudo-tetrasaccharide $\alpha$-glucoside inhibitor used as a hypoglycemic in the treatment of type 2 diabetes mellitus, was used as a positive control.

It is noticed that the control group, which received only starch, presented high levels of glucose in the blood. The mean glycemic peak for these animals $\left(154 \mathrm{mg} \mathrm{dL}^{-1}\right)$ occurred 30 min after the ingestion of starch and tended to decrease 

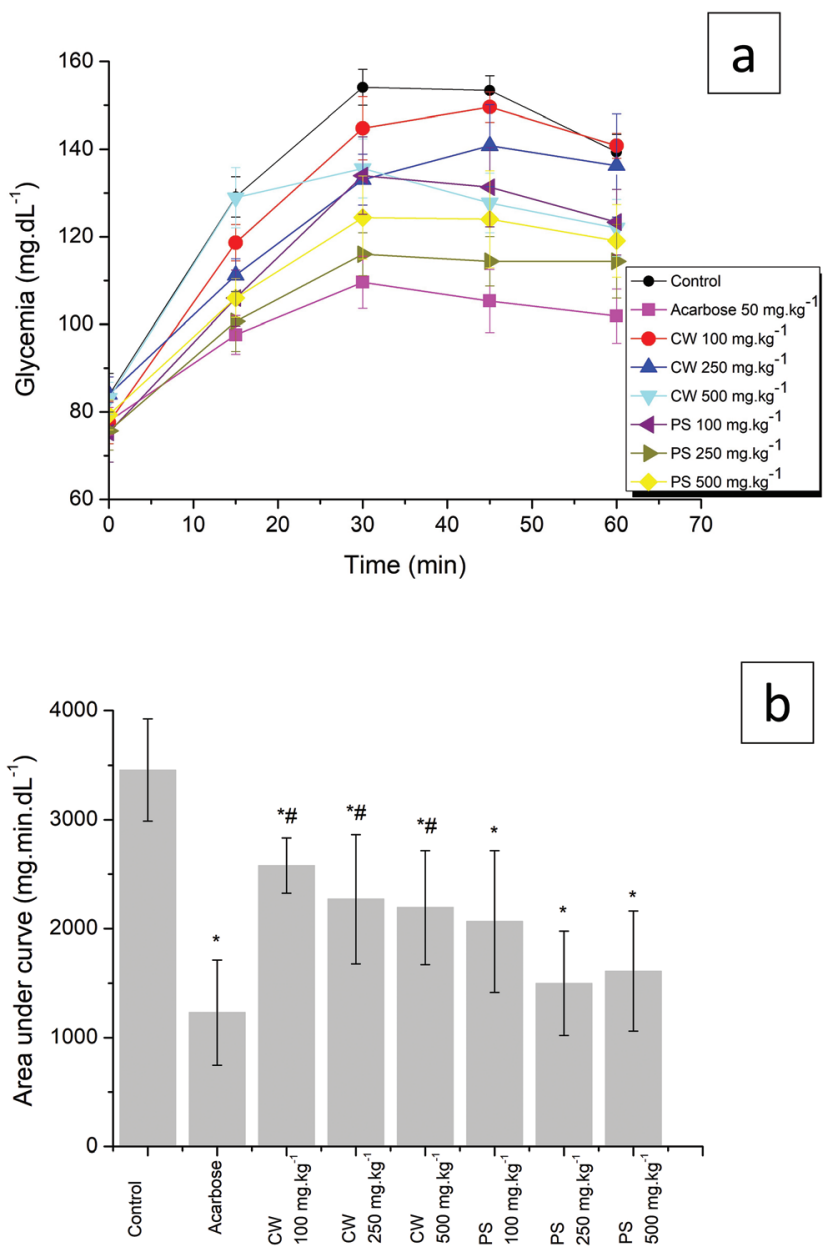

Fig. 2 (a) Blood glucose concentration profiles after intragastric starch provision in rats showing the effects of the pinhão extracts (WC and PS). The oral administration of maize starch ( $1 \mathrm{~g}$ per $\mathrm{kg}$ of body weight) was done immediately after the oral administration of the extract or acarbose. Plasma glucose was measured as described in the methods section. Each value represents a mean \pm mean standard error value from $5-7$ rats. (b) The areas under the curve obtained after various treatments with pinhão extracts (WC and PS) illustrated in panel (a) in comparison with the area under the curve obtained after water administration; * indicates statistical significance relative to the control $(p<0.05) ;{ }^{\#}$ indicates statistical significance relative to the acarbose group $(p<0.01)$.

from 45 min onward. Acarbose efficiently decreased glycaemia, and $30 \mathrm{~min}$ after the ingestion of starch (Fig. 2A), this glycaemia was $30 \%$ lower in relation to the control $(p<0.05)$. In relation to the total glucose absorbed $1 \mathrm{~h}$ after starch ingestion (area under the curve, Fig. 2B), it is possible to notice that there was a $64 \%$ decrease in response to acarbose in comparison with the control group.

The CW extract was able to significantly decrease glycaemia in the animals, but it was less efficient than acarbose at the tested concentrations. Thirty minutes after ingestion of starch (Fig. 2A), the glycaemia of animals treated with the CW extract was $13 \%, 18 \%$, and $17 \%$ lower than the control $(p<0.05)$ for concentrations of 100,250 , and $500 \mathrm{mg} \mathrm{kg}^{-1}$, respectively. When analyzing the total absorbed glucose in $1 \mathrm{~h}$ (Fig. 2B), the administration of $\mathrm{CW}$ extract resulted in decreases of $25 \%$, $34 \%$, and $36 \%$ in the glycaemia of the animals in relation to the control group at concentrations of 100, 250, and $500 \mathrm{mg}$ $\mathrm{kg}^{-1}$, respectively.

On the other hand, the PS extract did not differ significantly from acarbose, showing decreases of $40 \%, 56 \%$, and $53 \%$ in the total glucose absorbed by animals that ingested concentrations of 100,250 , and $500 \mathrm{mg} \mathrm{kg}^{-1}$, respectively, in relation to the control group. These results confirm the data from in vitro analysis, where the extract from pinhão shells had a higher inhibitory effect against $\alpha$-amylase compared to the cooking water extract.

Studies have shown that extracts obtained from other seeds, nuts, and legumes also have significant effects on glycemic control when tested in vivo. Methanolic and ethyl acetate extracts from Pinus gerardiana nuts were administered to diabetic mice for 14 days, and a reduction in the glucose level was observed mainly at a concentration of $750 \mathrm{mg} \mathrm{kg}^{-1} \cdot{ }^{37}$ In another study, black soybean seed coat extract was evaluated for treating mice with a high-fat diet and streptozotocin-induced diabetes by Chen et al. ${ }^{40}$ The food and water intake, body weight loss, and blood glucose and insulin levels of the group treated with the extract were found to be significantly reduced when compared with the diabetic mice group $(p<0.05)$. The fasting blood glucose level and insulin level of the group treated with extract at $400 \mathrm{mg} \mathrm{kg}{ }^{-1}$ were significantly decreased by $47.97 \%$ and $46.49 \%$, respectively. Also, Lima et al. ${ }^{41}$ developed a nanosuspension of $A$. angustifolia seed coats, in which nanofibrils with antioxidant activity and high levels of phenols and sterols led to a decrease in cholesterol, triglyceride, and glucose levels and weight gain in rats when they were treated with a daily diet containing this nanosuspension.

The results of $\alpha$-amylase inhibition tests in vivo and in vitro demonstrate that these extracts could possibly be used to minimize the effects of postprandial hyperglycemia, especially in diabetic patients. The extracts still need to be evaluated in humans, but the results show potential for application.

Oliveira et al., ${ }^{42}$ through in vitro and in vivo tests, observed that pinhão shell extract showed inhibitory effects toward pancreatic lipase, being able to reduce the triglyceride levels in the blood plasma of mice. This is an interesting property that complements inhibitory activity against $\alpha$-amylase, since the inhibition of these two enzymes together can contribute to a reduction in or the control of body weight, these being important issues for patients with type 2 diabetes.

\subsection{In vitro activity analysis of cholinesterases: acetylcholinesterase (AChE) and butyryl cholinesterase (BChE)}

Table 2 shows the concentrations required to reduce the cholinesterase enzyme activity to $50 \%$ of its initial value.

When analyzing the $\mathrm{IC}_{50}$ values, it is observed that the $\mathrm{CW}$ extract presented lower inhibition concentrations when compared to the PS extract with regard to the activities of both enzymes. However, both extracts exhibited potential to act as cholinesterase inhibitors, which could contribute to an increase in acetylcholine availability in the synaptic cleft, con- 
Table 3 Cytotoxicity levels $\left(\mathrm{Gl}_{50}\right.$ values, $\left.\mu \mathrm{g} \mathrm{mL}^{-1}\right)$ and anti-inflammatory activities $\left(\mathrm{IC}_{50}\right.$ values, $\mu \mathrm{g} \mathrm{mL^{-1 }}$ ) of the cooking water and pinhão shell extracts (mean \pm SD)

\begin{tabular}{|c|c|c|}
\hline & CW & PS \\
\hline \multicolumn{3}{|l|}{ 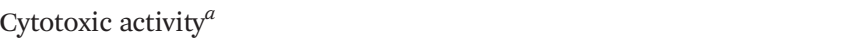 } \\
\hline NCl-H460 (non-small cell lung carcinoma) & $>400$ & $278.87 \pm 6.10$ \\
\hline HeLa (cervical carcinoma) & $>400$ & $250.99 \pm 8.37$ \\
\hline HepG2 (hepatocellular carcinoma) & $>400$ & $226.75 \pm 14.62$ \\
\hline MCF-7 (breast carcinoma) & $>400$ & $314.45 \pm 9.34$ \\
\hline PLP2 (porcine liver primary cells) & $>400$ & $>400$ \\
\hline \multicolumn{3}{|l|}{ Anti-inflammatory activity ${ }^{b}$} \\
\hline RAW 264.7 (murine macrophages) & $>400$ & $>400$ \\
\hline \multicolumn{3}{|c|}{ 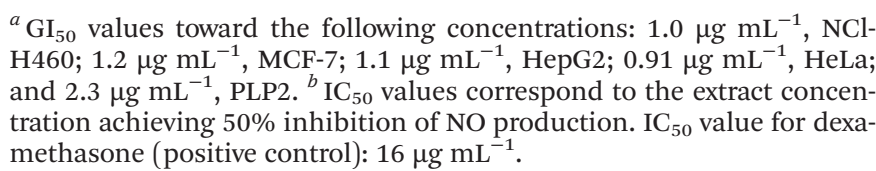 } \\
\hline
\end{tabular}

sequently leading to the more efficient transmission of nervous impulses and the proper functioning of the cholinergic system. ${ }^{43}$

Carrazoni et al. $^{44}$ administered an Araucaria angustifolia needle extract to Nauphoeta cinerea cockroaches and verified significant differences in the action of acetylcholinesterase as a result of extract effects at concentrations of 200 and $400 \mu \mathrm{g} \mathrm{g}^{-1}$.

\subsection{Cytotoxic assays using cell lines and anti-inflammatory activities}

Table 3 shows the results obtained from cytotoxicity analysis using human tumor cell lines and the anti-inflammatory activities of CW and PS extracts.

It can be noticed that at the studied concentrations, CW extract was not able to inhibit any of the investigated cancer cells. On the other hand, the PS extract demonstrated cytotoxic activity toward all the human tumor lines investigated. Additionally, the PS extract was most effective against hepatocellular carcinoma.

Baranei et al. ${ }^{45}$ when evaluating the cytotoxicity of greentea-loaded particles, observed reductions in the viabilities of different cell lines (MCF-7, HepG2, and HL-60). That research pointed out that compounds such as catechin and some flavonoids present in teas demonstrate inhibitory effects against the growth of cancerous cells. ${ }^{46}$ Thus, the higher concentration of catechin present in the PS extract may explain its higher cytotoxicity against the cell lines studied.

Furthermore, the concentrations analyzed for both extracts did not affect porcine liver cells (without any pathology), demonstrating that the extracts do not present cytotoxic effects against non-tumor cells. However, no anti-inflammatory activity was detected in the tested concentration range.

\section{Conclusions}

In general, out of the two extracts evaluated in the present work, pinhão shell extract presented significant antioxidant properties when evaluated via the DPPH method. Through in vitro tests it can be concluded that both extracts (CW and PS) acted as inhibitors of human salivary and porcine pancreatic $\alpha$-amylases. The pronounced effects resulting from the PS extract were associated with its phenolic composition, as determined via HPLC-DAD-ESI/MSn. In vivo analysis supported the hypothesis that the extracts acted as inhibitors of hydrolyzing enzymes, since there was a significant decrease in the blood glucose levels of rats treated with the extracts when compared to a control group.

Both extracts acted as inhibitors of cholinesterases; however, contrary to what was observed for $\alpha$-amylases, the best results were found for the $\mathrm{CW}$ extract. This indicates the application potential of the CW extract, but it is still necessary to carry out complementary in vivo investigations.

No cytotoxicity toward normal cells was shown by either extract. In the case of the pinhão shell extract, it showed cytotoxic activity against the different types of tumor cells evaluated. Ultimately, these results demonstrate the bioactivity of extracts obtained from pinhão bio-residues. The extracts can be considered as a possible alternative method for inhibiting enzymes ( $\alpha$-amylases and cholinesterases), and the PS extract is a potential anti-carcinogenic; however further complementary and in vivo studies are required.

\section{Conflicts of interest}

The authors declare that there are no conflicts of interest regarding the publication of this paper.

\section{Acknowledgements}

The authors thank CNPq (Chamada Universal - MCTI/CNPq No. 28/2018, Process 421541/2018-0) and Fundação Araucária (convênio 039/2019) for financial support. This study was financed in part by the Coordenação de Aperfeiçoamento de Pessoal de Nível Superior - Brasil (CAPES) - Finance Code 001. The authors thank Central Analítica Multiusuário da UTFPR Campo Mourão (CAMulti-CM) for analysis. Project POCI-010145-FEDER-006984 - Associated Laboratory LSRE-LCM was funded by FEDER funds through COMPETE2020 - Programa Operacional Competitividade e Internacionalização (POCI) and by national funds through FCT - Fundação para a Ciência e a Tecnologia. The authors are grateful to the Foundation for Science and Technology (FCT, Portugal) for financial support through national funds FCT/MCTES to CIMO (UIDB/00690/ 2020). M. I. Dias and L. Barros would like to acknowledge national funding from FCT, P. I., through the institutional scientific employment program-contract.

\section{References}

1 J. Aguiar, B. N. Estevinho and L. Santos, Trends Food Sci. Technol., 2016, 58, 21-39. 
2 H. Q. Dong, M. Li, F. Zhu, F. L. Liu and J. B. Huang, Food Chem., 2012, 130, 261-266.

3 I. Funke and M. F. Melzig, Rev. Bras. Farmacogn., 2006, 16, 1-5.

4 Z. M. Dastjerdi, F. Namjoyan and E. Azemi, Eur. J. Biol. Sci., 2015, 7, 26-31.

5 H. A. Jung, M. Y. Ali, H. J. Jung, H. O. Jeong, H. Y. Chung and J. S. Choi, J. Ethnopharmacol., 2016, 191, 152-160.

6 Q. Li, H. Yang, Y. Chen and H. Sun, Eur. J. Med. Chem., 2017, 132, 294-309.

7 R. J. Menéndez-Helman, G. V. Ferreyroa, M. dos Santos Afonso and A. Salibián, Ecotoxicol. Environ. Saf., 2015, 111, 236-241.

8 Y. Liu, B. Yan, D. A. Winkler, J. Fu and A. Zhang, Appl. Mater. Interfaces, 2017, 9, 18626-18638.

9 F. Rocha, L. Y. Sugahara, F. V. Leimann, S. M. De Oliveira, E. da S. Brum, R. C. Calhelha, M. F. Berreiro, I. C. F. R. Ferreira, R. P. Ineu and O. H. Gonçalves, Food Funct., 2018, 1-30.

10 J. Mehta, S. Rayalam and X. Wang, Antioxidants, 2018, 7, 1-20.

11 C. G. Araldi, C. M. M. Coelho, S. A. Gaziola and R. A. Azevedo, Acta Physiol. Plant., 2016, 38, 1-10.

12 C. D. S. Branco, É. D. De Lima, T. S. Rodrigues, T. B. Scheffel, G. Scola, C. C. F. C. Laurino, S. Moura and M. Salvador, Chem.-Biol. Interact., 2015, 231, 108-118.

13 R. M. Daudt, P. I. Back, N. S. M. Cardozo, L. D. F. Marczak and I. C. Külkamp-Guerreiro, Carbohydr. Polym., 2015, 134, 573-580.

14 S. M. da Silva, E. A. Koehnlein, A. Bracht, R. Castoldi, G. R. de Morais, M. L. Baesso, R. A. Peralta, C. G. M. de Souza, A. B. de Sá-Nakanishi and R. M. Peralta, Food Res. Int. , 2014, 56, 1-8.

15 T. B. De Freitas, C. H. K. Santos, M. V. da Silva, M. A. Shirai, M. I. Dias, L. Barros, M. F. Barreiro, I. C. F. R. Ferreira, O. H. Gonçalves and F. V. Leimann, Food Packag. Shelf Life, 2018, 15, 28-34.

16 C. H. K. Santos, M. R. Baqueta, A. Coqueiro, M. I. Dias, L. Barros, M. F. Barreiro, I. C. F. R. Ferreira, O. H. Gonçalves, E. Bona, M. V. da Silva and F. V. Leimann, Food Chem., 2018, 261, 216-223.

17 S. M. F. Bessada, J. C. M. Barreira, L. Barros, I. C. F. R. Ferreira and M. B. P. P. Oliveira, Ind. Crops Prod., 2016, 89, 45-51.

18 W. Brand-Williams, M. E. Cuvelier and C. Berset, Leb. + Technol., 1995, 28, 25-30.

19 G. L. Miller, Anal. Chem., 1959, 3, 426-428.

20 S. Wagon, Mathematica in action, Springer Science \& Business Media, 1999.

21 G. L. Ellman, K. D. Courtney, V. Andres and R. M. Featherstone, Biochem. Pharmacol., 1961, 7, 88-95.

22 I. S. de Sá, A. P. Peron, F. V. Leimann, G. N. Bressan, B. N. Krum, R. Fachinetto, J. Pinela, R. C. Calhelha, M. F. Barreiro, I. C. F. R. Ferreira, O. H. Gonçalves and R. P. Ineu, Food Chem. Toxicol., 2019, 125, 29-37.

23 R. M. V. Abreu, I. C. F. R. Ferreira, R. C. Calhelha, R. T. Lima, M. H. Vasconcelos, F. Adega, R. Chaves and M. J. R. P. Queiroz, Eur. J. Med. Chem., 2011, 46, 5800-5806.
24 F. Sobral, A. Sampaio, S. Falcão, M. J. R. P. Queiroz, R. C. Calhelha, M. Vilas-Boas and I. C. F. R. Ferreira, Food Chem. Toxicol., 2016, 94, 172-177.

25 J. T. do Prado Silva, J. M. T. Geiss, S. M. Oliveira, E. da S. Brum, S. C. Sagae, D. Becker, F. V. Leimann, R. P. Ineu, G. P. Guerra and O. H. Gonçalves, Mater. Sci. Eng., C, 2017, 76, 1005-1011.

26 J. C. Perotti, K. C. da Silva Rodrigues-Corrêa and A. G. FettNeto, Plant Biol., 2015, 17, 852-859.

27 S. Yamamoto, A. Otto and B. R. T. Simoneit, J. Mass Spectrom., 2004, 39, 1337-1347.

28 C. G. Tsanaktsidis, E. P. Favvas, A. A. Scaltsoyiannes, S. G. Christidis, E. X. Katsidi and A. V. Scaltsoyiannes, Fuel Process. Technol., 2013, 114, 135-143.

29 F. V. Leimann, O. H. Gonçalves, G. D. Sorita, S. Rezende, E. Bona and I. P. M. Fernandes, Chem. Eng. Sci., 2019, 205, 248-258.

30 T. B. V. Da Silva, T. F. M. Moreira, A. De Oliveira, A. P. Bilck, O. H. Gonçalves, I. C. F. R. Ferreira, L. Barros, M.-F. Barreiro, F. Yamashita, M. A. Shirai and F. V. Leimann, Food Funct., 2019, (12), 7697-7706.

31 E. P. da Cruz, L. M. Fonseca, M. Radünz, F. T. da Silva, E. A. Gandra, E. da R. Zavareze and C. D. Borges, J. Food Sci., 2021, 86(7), 2886-2897.

32 F. H. A. Fernandes, C. P. Santana, R. L. Santos, L. P. Correia, M. M. Conceição, R. O. Macêdo and A. C. D. Medeiros, J. Therm. Anal. Calorim., 2013, 113(2), 443-447.

33 L. M. Fonseca, J. P. de Oliveira, R. L. Crizel, F. T. da Silva, E. da Rosa Zavareze and C. D. Borges, Food Biophys., 2020, 355-367.

34 K. C. de Souza, L. G. Correa, T. B. V. da Silva, T. F. M. Moreira, A. de Oliveira, L. S. Sakanaka, M. I. Dias, L. Barros, I. C. F. R. Ferreira, P. Valderrama, F. V. Leimann and M. A. Shirai, Food Bioprocess Technol., 2020, 13, 9981008.

35 T. F. Vieira, G. Yasuo, F. Makimori, M. Brígida, A. Antonio, F. Zielinski and E. Bona, Food Anal. Methods, 2020, 13, 97107.

36 G. S. T. da Mota, A. B. Arantes, G. Sacchetti, A. Spagnoletti, P. Ziosi, E. Scalambra, S. Vertuani and S. Manfredini, J. Cosmet., Dermatol. Sci. Appl., 2014, 4, 190-202.

37 F. Zulfqar, M. F. Akhtar, A. Sharif, U. Saleem, A. Saleem and B. Akhtar, J. Food Biochem., 2020, 44, 1-12.

38 T. Tsujita, T. Shintani and H. Sato, J. Agric. Food Chem., 2013, 4570-4576.

39 G. Schmeda-Hirschmann, J. Antileo-Laurie, C. Theoduloz, F. Jiménez-Aspee, F. Avila, A. Burgos-Edwards and V. OlateOlave, Food Chem., 2021, 350, DOI: 10.1016/j. foodchem.2021.129241.

40 Z. Chen, C. Wang, Y. Pan, X. Gao and H. Chen, Food Funct., 2018, 9(1), 426-439.

41 G. G. de Lima, N. B. de Miranda, T. G. Timm, M. Matos, T. A. M. de Lima, W. L. E. Magalhães, L. B. B. Tavares, F. A. Hansel and C. V. Helm, Food Funct., 2020, (11), 98209832. 
42 R. F. Oliveira, G. A. Gonçalves, F. D. Inácio, E. A. Koehnlein, C. G. M. de Souza, A. Bracht and R. M. Peralta, Nutrients, 2015, 7, 5601-5614.

43 L. G. De Souza, M. N. Rennó and J. D. Figueroa-villar, Chem.-Biol. Interact., 2016, 254, 11-23.

44 T. Carrazoni, P. D. B. Vieira, P. G. da Silva, M. D. A. Heberle, G. D. Sturmer, M. S. Correa,
A. B. Pereira, S. Moura, A. S. Mendez and C. A. Dal Belo, Journal of Botany Research, 2017, 1(1), 38-49.

45 M. Baranei, R. A. Taheri, M. Tirgar, A. Saeidi, F. Oroojalian, L. Uzun, A. Asefnejad, F. R. Wurm and V. Goodarzi, Mater. Today Commun., 2020, 101751.

46 Y. Q. Xu, Y. Gao and D. Granato, Food Chem., 2021, 339, 128060. 